\title{
Erratum to: An Informational Ontology and Epistemology of Cognition
}

\author{
Kun Wu • Joseph E. Brenner
}

Published online: 1 November 2014

C) Springer Science+Business Media Dordrecht 2014

\section{Erratum to: Found Sci \\ DOI 10.1007/s10699-014-9364-0}

The author, Kun Wu's name, affiliation and biography have been incorrectly published in the original article. The correct affiliation and biography are provided below.

\begin{abstract}
Kun Wu was born in 1953 in the People's Republic of China. He is at present Professor, Doctoral Advisor and Director of The International Center for the Philosophy of Science of the Xi' an Jiaotong University College of Humanities and Social Sciences, as well as member of the Chinese State Council of Experts. In 1980, Professor Kun Wu started his development of the field of the philosophy of information. Since then, he has published 13 monographs, two translations, written or edited four textbooks and published more than 330 academic papers. Wu's main academic contribution takes the concept of information as a the basic category of philosophy, establishing a philosophy of information which includes information ontology, information epistemology, social information theory, information theory of evolution, information value theory and information theory of thinking. The originality of this research is its discussion of modern philosophical problems in systems science, natural philosophy, value philosophy, the information and knowledge economy, information science, entropy theory, complexity theory and some other broad philosophical, economic and scientific areas. He has also applied information science and philosophy as well as the methods of complexity theory to ancient theories of philosophy, for example from Greece, China and India. His founding of a theory of the philosophy of information attracted wide attention in China: two of his research publications, "The summary of the philosophy of information" ("The Journal of humanities," 1985, 1) as well as "Introduction to the Philosophy of information" (Shanxi People's Publishing House, 1987) have been seen in China as the foundation of the philosophy of information. Wu's major 2005 book, Philosophy of Information - Theory, System and Method, is demonstration of the maturity and scope of his philosophy of information for which he has been praised as "the pioneer of the philosophy of information" and "philosophy of information in the first person."
\end{abstract}

The online version of the original article can be found under doi:10.1007/s10699-014-9364-0.

K. Wu

International Center for the Philosophy of Information,

Xi'an Jiaotong University, Xi' an, China

J. E. Brenner $(\varangle)$

Les Diablerets, Switzerland

e-mail: brenner52@sbcglobal.net 